\title{
Effect of Suppressants on Metal Fires
}

T.J. Ohlemiller and J.R. Shields

Building and Fire Research Laboratory

Gaithersburg, Maryland 20899

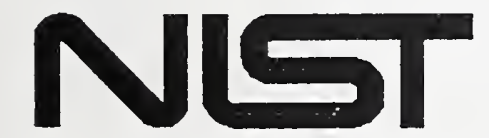

United States Department of Commerce

$$
\text { logy Administration }
$$

QC

al Institute of Standards and Technology

100

.056

N0.5710 



\section{Effect of Suppressants on Metal Fires}

T.J. Ohlemiller and J.R. Shields

\section{August, 1995}

Building and Fire Research Laboratory

National Institute of Standards and Technology

Gaithersburg, MD 20899

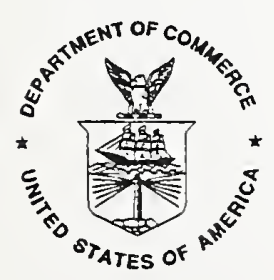

U.S. Department of Commerce

Ronald H. Brown, Secretary

Technology Administration

Mary L. Good, Under Secretary for Technology

National Institute of Standards and Technology

Arati Prabhakar, Director 

TABLE OF CONTENTS

Abstract

Introduction

Description of Apparatus

Burn Configuration

Combustion Chamber

Flow System

Sample Ignition

Test Materials

Data Acquisition

Results and Discussion

Magnesium

Titanium

7

Conclusions

References 



\title{
Effect of Suppressants on Metal Fires
}

\author{
Thomas J. Ohlemiller and John R. Shields \\ Building and Fire Research Laboratory
}

\begin{abstract}
As part of a study to determine the impact of halon-alternative fire suppression agents on metal fires, small diameter rods (ca. 1-2 mm) of magnesium and titanium were burned in oxidizing atmospheres containing various percentages of agent vapor. Magnesium was burned in flowing air at pressures of 0.27 and $0.79 \mathrm{MPa}$ (25 and 100 psig). Add-on levels of $5 \%$ and, in some cases $10 \%$, by weight of halon 1301, HFC125, HFC-227ea, FC-218 and $\mathrm{CF}_{3} \mathrm{I}$ were examined. In all cases, the burning, which had been vigorously established before agent vapor introduction, was extinguished. Titanium was burned in a flowing oxidizing gas containing 40 to $50 \%$ oxygen in nitrogen at pressures from 0.31 to $0.79 \mathrm{MPa}$ (30 to $100 \mathrm{psig}$ ). Here only halon 1301 , HFC-125 and HFC-227ea were added on, at $10 \%$ and $15 \%$ by weight. All three of these agents slowed, or, in certain cases extinguished, the burning process. Very limited data showed HFC-227ea to slow the burning rate less than did an equal add-on of HFC-125 or halon 1301. The suppressive impact of the agent vapors seen in this study is counter to that in previous studies where burning enhancement has been seen.
\end{abstract}

\section{Introduction}

This study is focussed on two specific metals, magnesium and titanium. These metals, usually in the form of various alloys, are utilized in several locations in modern military aircraft. Magnesium is used extensively in structural areas of aircraft; titanium also has structural uses but is most commonly found in jet engines, for example, as compressor and turbine blades.

These metals, and alloys dominated by them, are flammable. Ignition of these metals requires that they be heated to near their melting points: $c a .650{ }^{\circ} \mathrm{C}$ for magnesium and $c a .1800{ }^{\circ} \mathrm{C}$ for titanium (somewhat lower for alloys). Their ease of ignition is much less than that of familiar solid organic materials such as polymers which typically ignite when heated to $300-400{ }^{\circ} \mathrm{C}$. Bringing the metal surface to its ignition temperature is also more difficult than it is for organic materials (i.e., it requires a higher heat flux) because the metals have much higher thermal inertia values, thus requiring more heat to achieve a given surface temperature (Elrod et al., 1980).

Once ignited both metals are capable of intense, high temperature burning ${ }^{1}$ as a result of the very high heats of formation of their oxides. Titanium requires more restrictive conditions for continued combustion than does magnesium, at least in part because its oxide accumulates in the molten metal surface region, slowing the rate of oxidation (Clark, Moulder and Runyan, 1975). As a result, contin-

\footnotetext{
${ }^{1}$ In pure oxygen at one atmosphere pressure, the adiabatic combustion temperatures of magnesium and titanium are both approximately $3000^{\circ} \mathrm{C}$ (Strobridge et al., 1979).
} 
ued combustion requires either a significant pre-heating of the metal, elevated oxygen partial pressure or shearing away of the molten oxide/metal layer (Clark, Moulder and Runyan, 1975; Rhein and Baldwin, 1980). All of these conditions can be found in jet engines; the shearing is provided by the high velocity of the gases and centrifugal forces (Fox, 1976; Anderson and Manty, 1978; Elrod and Lyon; 1979; Strobridge et al., 1979; Rhein and Baldwin, 1980; Elrod et al., 1982; Baldwin et al., 1984).

The current study is directed toward the interaction of suppressants with these burning metals. Although it is possible for the metal alone to be the burning material in need of suppression, the concern here is broader. Military aircraft fires in general are most frequently suppressed with halons. A fire may start with a fuel or hydraulic fluid leak and spread, involving parts composed of magnesium or titanium. This fire will be manually or automatically flooded with halon compounds (or, in the future, their replacements). The use of halogen-containing suppressant agents on pure metal fires is considered hazardous and is not recommended (Andrews, 1981) but in the mixed materials environment of a military aircraft, where a fuel fire is the more likely threat, they are used, regardless of the possible involvement of metal aircraft components. Experience to date, based on halon suppressants, shows that this is an effective approach. The work here specifically addresses the concern of whether candidate halon replacements will pose any greater hazard in their interaction with a metal fire than do the currently used halons.

Halogens, particularly fluorine, can combine with magnesium or titanium with an evolution of more heat than is obtained from combining with oxygen. The heat of formation of magnesium fluoride is $83 \%$ higher than that of magnesium oxide. For titanium there are several possible products but the most relevant comparison is probably titanium tetrafluoride which has a heat of formation that is $70 \%$ higher than that of titanium dioxide. Simple calculations (below) suggest that under some conditions either of these metals might strip the halogens from a halon such as halon 1301 and evolve more heat than could be obtained from reaction with oxygen. Thus the suppressant could become an accelerant. There are warnings in the literature regarding this (McCutchan, 1954; Maykuth, 1964; Kuchta et al., 1965 \& 1966; NASA, 1970; Rhein \& Baldwin, 1980; Tapscott, et al., 1986). Unfortunately, most of these references describe experiments in which the effect of a halogen-containing agent on a metal fire cannot be clearly quantified. The fires are qualitatively observed to "accelerate" or "flare-up" when sprayed with the halon agent from an extinguisher. The possible role of purely physical factors, such as intensification due to scattering of the burning metal by flash vaporization of liquid droplets of the halon, cannot be assessed.

Kuchta et al. (1966) did perform some more quantifiable experiments with heated titanium wires in hot gas streams containing the decomposition vapors of various halocarbons. Various halon vapors were heated to $450{ }^{\circ} \mathrm{C}$ and then passed over titanium wires at $600{ }^{\circ} \mathrm{C}$; the increase in wire temperature was measured. This increase should be reflective of the heat release rate due to reaction of the halon vapors with the wire surface. Halon 1301 gave the least increase in wire temperature of any halon examined though it was still significant. This result does confirm that halons will chemically react with titanium in an exothermic manner (under these conditions). The variation of effect with halon type implies kinetic effects, perhaps both in extent of vapor decomposition and in rate of attack on the metal. The data are too limited to resolve such issues.

The present study is limited to examining the effect of the vapors of various halogen-containing suppressants on the burning of pure magnesium and titanium rods in a slow flow of oxygen-containing gas. The test configuration was instrumented to allow quantitation of the effect of the vapors on the rate of burning. As will be seen, the results were not as the literature leads one to expect in that the metal burning process was always either slowed or extinguished under the range of conditions examined. 
The agents examined in the presence of burning magnesium included halon 1301 (the reference case), HFC-125, HFC-227ea, FC-218 and $\mathrm{CF}_{3} \mathrm{I}$. For titanium, time limitations narrowed the study to halon 1301, HFC-227ea ${ }^{2}$ and HFC-125.

\section{Description of Apparatus}

2.1 Burn Configuration. For both metals, the burning configuration was upward propagation along a thin rod with the oxidant gas flowing in the same (upward) direction. This configuration was chosen so that gravity, by causing dripping of the molten metal in the case of titanium, would provide the necessary fresh metal surface to yield sustained combustion. It was not feasible, in the time allotted for this study, to set up the high speed, elevated temperature flows used previously to study titanium combustion propagation under jet engine conditions. Upward propagation was chosen because Sato et al. (1983) showed that downward propagation can produce much more erratic results (i.e., highly variable propagation rates) due to the dripping molten metal haphazardly making contact with the rod as it flows/falls downward, causing spot ignition. Oxidant flow velocity levels were limited to low values by practical constraints on mass flows borne of the use of bottled gases.

2.2 Combustion Chamber. Figure 1a is a not-to-scale, cross-sectional sketch of the overall experiment; Figure $1 \mathrm{~b}$ is a scaled, cross-sectional assembly drawing of the combustion chamber. The chamber is made of brass and consists of three sections, assembled in such a way as to allow relatively convenient cleaning and sample replacement. The bottom section accepts the incoming gas flow and directs it upward. This section also includes fittings for a pair of electrodes used in the metal ignition process. This section includes, as well, a small cup to catch and quench the drips of molten metal. The middle section contains the sample rod $(16 \mathrm{~cm}$ long) suspended in the gas flow, between two windows for clear observation. The front window, through which a video camera records the burning process, is Pyrex. The rear window is Vycor which provides light transmission out to about $2.5 \mu \mathrm{m}$. A calibrated thermopile-type radiometer (Dexter Research Center, Model $2 \mathrm{M}-\mathrm{HS})^{3}$ views the burning rod through this latter window (a non-imaged view), providing a signal proportional to the radiative emissions of the burn zone. Early tests indicated that small burning particles emitted from the burning titanium rods could pit the windows (which are only about $2.5 \mathrm{~cm}$ from the burning rod). Thus the windows were lined with a thin $(0.25 \mathrm{~mm})$, reusable sheet of Kel-F polymer film which is essentially transparent to all of the radiation passing through the Vycor and Pyrex windows. The upper section of the chamber contains a bare wire thermopile consisting of four $0.125 \mathrm{~mm}$ diameter type $\mathrm{S}$ thermocouples wired in parallel; the four thermocouple junctions are arrayed in the flow. This thermopile samples the average temperature of the gases passing through the chamber downstream of the combustion

${ }^{2} \mathrm{HFC}-227 \mathrm{ea}$ is referred to in the remainder of this discussion simply as HFC-227.

${ }^{3}$ Certain trade names and company products are mentioned in the text or identified in an illustration in order to specify adequately the experimental procedure and equipment used. In no case does such identification imply recommendation or endorsement by the National Institute of Standards and Technology, nor does it imply that the products are necessarily the best available for the purpose. 
process; it thus provides a measure of the convective heat output of the burning process. This measure could be made absolute by calibration with an electrical energy source in the sample burning region; this was not done here because only relative performance (to halon 1301 as a baseline) was of interest.

The chamber can be operated at pressures up to $1.48 \mathrm{MPa}$ (200 psig). A burst disk is incorporated in the system because information on the possible flammability of mixtures of the candidate halon replacement agents in elevated oxygen atmospheres is not available. (It is known that some halogenated hydrocarbons are flammable in some oxygenated mixtures (Perlee, Martindill and Zabetakis, 1966).) A practical limit of 5 grams of incoming oxidant gas per second was imposed to accommodate the use of bottled gases and the limited supplies of some of the halon replacement agents. This fixed mass flow defines the outer envelope of achievable pressure and velocity conditions. The maximum oxidant flow velocity in the sample section thus varies from $3.7 \mathrm{~m} / \mathrm{s}$ at $0.1 \mathrm{MPa}$ (atmospheric pressure) to $0.27 \mathrm{~m} / \mathrm{s}$ at $1.48 \mathrm{MPa}$.

2.3 Flow System. Figure 2 is a schematic of the flow system in its simplest configuration, used when the agent vapor pressure at room temperature was sufficient to supply the desired add-on level to the oxidant flow. All pressures were measured with gages rated by the manufacturer at $\pm 0.5 \%$ accuracy. All flows were measured with rotameter-type flowmeters which had been calibrated with a dry test meter in the pressure and flow range of usage; flow accuracy is estimated to be $\pm 2-3 \%$.

Figure 2 shows that the agent vapor could be added upstream or downstream of the combustion chamber. As will be described below, this bypass feature was necessary because the agent vapor tended to attack the sample ignition system. When the agent was introduced upstream of the chamber, a static mixer assured concentration uniformity in the oxidant flow prior to the chamber.

When flow of an oxidant stronger than air was needed, it was obtained by mixing air and pure oxygen. This was done using a two tube, mixing rotameter for which both tubes were calibrated as above. It should be noted that oxygen level data reported here are those prior to the agent vapor addon.

In order to operate the chamber at pressures above the room temperature vapor pressure of the agent of interest, it is necessary to meter and introduce the agent as a liquid, mix it with the oxidant gas in a heater section then cool the total flow back to room temperature. A system to achieve this was in fact built. However, when it was found that the agent vapors attacked the ignition system, this approach had to be discontinued. In the flow system shown in Figure 2, the agent vapor needs to be added a short distance upstream of the chamber so that the flow time to the chamber is short (compared to the sample burn time). The system required to vaporize the agent with heating and then cool the entire gas stream was several meters in length. In some conditions, the sample could have burned excessively before the agent vapor reached it. Thus all tests were confined to pressure conditions in which the desired agent level could be achieved using the vapors in the headspace above a liquid agent reservoir.

2.4 Sample Ignition. Ignition of the small diameter metal rods proved to be more problematical than expected. For magnesium, copper electrodes were used in the base of the combustion chamber to supply electrical current to a nichrome heating wire from a low voltage DC power supply. One end of a length (about $4 \mathrm{~cm}$ ) of magnesium ribbon $(0.25 \mathrm{~mm}$ thick by $3 \mathrm{~mm}$ wide) was wound around the bottom few $\mathrm{mm}$ of the sample rod; the other end was folded over the nichrome wire. Heating of the nichrome wire was to ignite the magnesium ribbon and the ribbon would ignite the rod. This was satisfactory as long as there was no agent vapor in the oxidant flow. When agent vapor was present, it attacked the nichrome wire, frequently causing it to break before the magnesium ribbon could ignite. This behavior necessitated the agent vapor bypass path shown in Figure 2. With this in place, the agent vapor was introduced into the chamber exhaust line during the sample ignition process; this 
allowed the agent flow system to achieve a steady-state condition. When the sample rod had clearly ignited and propagated combustion $1-2 \mathrm{~cm}$, the agent vapor was switched into the chamber inlet line, reaching the sample burn zone a few seconds later.

Titanium, with its much higher melting point, could not be ignited in the above manner, even though the sample rod was only about $1 \mathrm{~mm}$ in diameter. An attempt was made to use an electric arc welder boosted by a high frequency, high voltage arc stabilizer in the manner of Baldwin, Beach and Rhein (1984). The arc welder itself was rated at 230 amperes AC; the arc stabilizer superimposed 3500 VAC of radio frequency oscillations to assist in arc formation and retention. The arc stabilizer proved to be totally ineffective for reasons which could not be established; it would not assist in arc formation even for atmospheric air gaps of a small fraction of a millimeter. Furthermore, it was very disruptive to the data acquisition system despite careful attempts at electromagnetic shielding. Ultimately, it was found that the titanium rods could be ignited by the contact resistance heating between tungsten electrodes and the surface of the sample rod. This required about 200 amperes and took as much as $20-30$ seconds to yield ignition.

The combustion of the sample was recorded with a Hi-8 video camera which viewed the sample through a \#12 welder's light filter. Progress of the propagation was also sensed by three blackened thermocouples $(0.13 \mathrm{~mm}$ diameter; chromel/alumel) recessed into the sidewall of the middle section of the combustion chamber at intervals of $4.0 \mathrm{~cm}$. Radiative heating of these was sufficient to yield a peak in voltage output as the combustion zone passed the thermocouple location.

2.5 Test Materials. The $1.6 \mathrm{~mm}$ diameter magnesium rod was $99.9 \%$ pure. It appeared to have been extruded. The titanium rod was $1.14 \mathrm{~mm}$ in diameter; it was commercially pure grade, used for welding purposes. It appeared to be wire-drawn. The initial focus of the titanium work had been on alloy 6-2-4-2 (6\% aluminum, $2 \%$ molybdenum, $4 \%$ zirconium and $2 \%$ tin) which is one of several forms in which titanium is frequently used in aircraft. However, it was found that ignition of the available $3 \mathrm{~mm}$ square rod required an atmosphere of more than $60 \%$ oxygen. This alloy could not be obtained in the small diameter which the above ignition system could more readily handle. Thus the focus was shifted to the pure metal, obtainable in the smaller diameter form. The qualitative conclusions of this work are believed to be applicable to high titanium alloys as well as the pure metal used here.

2.6 Data Acquisition. All data channels were hard-wired to a Strawberry Tree Workmate data acquisition board through an isothermal terminal board. Strawberry Tree Quicklog software was used as the data acquisition program. Data were acquired at $2 \mathrm{~Hz}$ with 14 bit resolution.

\section{Results and Discussion}

3.1 Magnesium. An initial short series of tests was conducted using pure air with no added agent to explore the possible sensitivity of the burning rate to other test parameters. Table 1 shows the results of varying both the chamber pressure and gas flow velocity in the test section. Chamber pressure was varied from $0.24 \mathrm{MPa}(20 \mathrm{psig})$ to $0.79 \mathrm{MPa}(100 \mathrm{psig})$; air flow velocity in the test section was varied from 13 to $42 \mathrm{~cm} / \mathrm{s}$. Note that the mass flow rate of air was held constant at one of two values which differed by $42 \%$.

Chamber pressure variation at a constant air mass flux will hold the mass transfer rate of oxygen to the burn zone constant while varying the gas phase chemical reaction rates between magnesium vapor and oxygen. This is done in the first four tests of Table 1. In the next three tests, the pressure (and thus the chemical reaction rate) is held constant but the mass flux is increased to enhance the 
oxygen mass transfer rate. Here the $42 \%$ increase in mass flux will yield roughly a $20 \%$ increase in mass transfer rate since the mass transfer coefficient is approximately proportional to the square root of Reynolds Number for this configuration (Bird, Stewart and Lightfoot, 1960).

No effect on burning rate from either of these changes clearly emerges from the data of Table 1. The average burning rate at the lower air mass flow rate is $3.9 \pm 0.3 \mathrm{~mm} / \mathrm{s}$; at the higher mass flow rate it is $3.6 \pm 0.4 \mathrm{~mm} / \mathrm{s}$. Here the uncertainties given are one standard deviation. The overlapping uncertainties preclude any inference of a trend. It is noteworthy, however, that the much larger percentage change in pressure (ca. $300 \%$ for absolute pressure) did not clearly affect burning rate. This implies that the gas phase chemical reaction rate is not the controlling step here. The data are ambiguous on the possible control by oxygen mass transfer, but they are not inconsistent with this idea.

It is also noteworthy that the burning rate is not particularly sensitive to gas mass flow rate or to pressure so that the effects of any slight variations in these will not be confused with agent vapor effects in the results below. Unfortunately, one reason that no effects of these variables emerge in Table 1 is that the data are somewhat noisy. The source of the noise appears to have been the rather complex nature of the combustion zone. The magnesium oxide did not simply condense to an aerosol and float away in the gas flow. Rather, a large fraction of the oxide condensed locally around the immediate area where the magnesium vapors were emerging from the burning rod, ultimately leaving a rough replica of the rod behind, attached to the unburned portion. (This tendency for the oxide to form complex solid structures in the region of the burning zone has been noted in previous studies (Law and Williams, 1974).) Here, the condensation process seemed to interfere with the vaporization/burning process so that the burn zone was irregular and extended of the order of ten rod diameters. Varying heat transfer to the metal through the irregular oxide mass probably caused the burning rate to vary. This irregular burn zone also had the potential to fool the three sensor thermocouples in the side of the chamber, originally intended to provide burning rate information. Thus all of the burning rate information was obtained instead from the video tapes of the tests where the leading edge of the burn zone could be easily followed.

Table 2 shows the result of adding on 5 or 10 weight percent of various agent vapors to the pressurized air flowing past the burning magnesium. Note that at least two replicates were run at each test condition. The surprising result in all cases was extinction of what was initially a vigorously propagating burning zone. (Recall that the sample rod was burning for about $2 \mathrm{~cm}$ before the agent vapor reached it.) Extinction typically occurred in 5-10 seconds, which is probably not much longer than the time to fully displace the agent-free atmosphere around the burning zone. ${ }^{4}$ Note that these add-on levels are low compared to those previously found necessary to extinguish various hydrocarbon flames (Hamins et al., 1994) in a fairly similar situation (cup burner). For hydrocarbons, an add-on level of $25-30 \%$ agent vapor to air was typically necessary. (Halon 1301 and $\mathrm{CF}_{3}$ I were exceptions, with the former requiring only 12-28 \% add-on by weight and the latter, equally effective on a molar basis, about $25 \%$ less than this on a mass basis.)

The reason for the present results is not clear. There is no obvious chemical basis for expecting the agents to act as suppressants here. Halon 1301 is believed to achieve its suppressant effect in hydrocarbon flames by trapping hydrogen radicals (Nyden and Linteris, 1994). Such radicals are not involved in magnesium burning (Tapscott et al., 1986). Most, if not all, of the extinguishing effectiveness in hydrocarbon fires of the halon alternative agents examined here (except $\mathrm{CF}_{3} \mathrm{I}$ ) was attributed to the simple physical effect of thermal dilution (Hamins et al., 1994). That is, these agents,

\footnotetext{
${ }^{4}$ Two tests, Mg-44 and Mg-45, with FC-218 were appreciably slower, with roughly $2 / 3$ of the rod consumed before extinction occurred.
} 
by their heat capacity effects, simply reduce the flame temperature to the point of extinguishment. A similar effect may be responsible here but the substantially lower agent concentrations $(<5 \%$ by weight) make this less likely.

A few tests were run with nitrogen added-on at 10 weight percent to the air flow. Table 1 shows that this had no significant effect on the measured burning rate at $0.79 \mathrm{MPa}(100 \mathrm{psig})$. This result is ambiguous, however, because nitrogen, which, of course, is the dominant gas in the air, may not be a passive diluent in this system. Magnesium nitride has a heat of formation that is $75 \%$ of that of magnesium oxide. Thus magnesium can burn in pure nitrogen. Whether nitride formation is significant (and thus whether the add-on was a diluent or a reactant) in the present experiments depends on its ability to compete with the oxygen/magnesium kinetics. Experiments in argon/oxygen mixtures could probably resolve the issue of whether an equivalent thermal capacitance ${ }^{5}$ of a truly inert diluent is capable of extinguishing the burning magnesium. There was insufficient time in the present study to pursue this issue further.

Some simple calculations, reported below with the titanium results, do, in fact, suggest a very weak slowing effect on the burning rate (not extinction) is possible for the conditions used here. As will be seen, the basis for this is oxygen dilution and retarded mass transfer of the alternative oxidant.

In spite of the incomplete picture as to the causes underlying the results in Table 2, those results do indicate that, at least down to the $5 \%$ add-on level, there is no difference in the impact of the old and new agents. Halon 1301 and the four candidate agents tested here are equally prone to extinguishing the burning process in this configuration. Differences could exist in the minimum add-on level required for extinguishment. This would require substantially more testing to establish.

It should be noted that the burning configuration used here incorporates no radiative self-feedback of energy among surface elements of the fuel. Such feedback stabilizes the combustion of any solid fuel, making it more difficult to extinguish. Thus the present result indicating that 5 or 10 weight percent of these agent vapors can extinguish a burning magnesium rod does not necessarily carry over to more complex configurations, such as would be encountered in a burning aircraft structural fire.

3.2 Titanium. The test conditions and burning rate results for titanium are summarized in Table 3 . The tests here are less extensive than with magnesium due to time constraints. Note that, in the tests done with no agent present, cutting the absolute pressure by greater than a factor of two (at a fixed mass flow rate) and increasing the ambient oxygen level by only $20 \%$ yielded a roughly $30 \%$ increase in the linear burning rate. This suggests (but does not prove) that mass transfer of oxygen is an important controlling factor. Since the oxidation reaction is evidently mainly heterogeneous here, within the molten oxide/metal mix (Clark et al., 1975), it is likely to be largely uninfluenced by the noted pressure change.

Note that the no-agent burn velocities for titanium are generally significantly less than those for magnesium, despite that fact that the ambient oxygen level is considerably higher in the titanium cases. Burning rate models for metals such as that of Sato and Hirano (1988) should aid in explaining such differences but the requisite kinetic data on the oxidation reactions are not available. Thus the reasons for these differences are not clear at present but a wide variety of property differences between the two metals could be contributing.

In all of these tests (including those with agents present in the ambient atmosphere) the behavior of the burning metal was non-steady. A glow zone would progress up the metal rod several (up to

${ }^{5}$ Thermal capacitance here means mass of the diluent times its heat capacity $\left(\mathrm{J} / \mathrm{g}{ }^{\circ} \mathrm{C}\right)$. Argon has less than half the heat capacity of nitrogen so its weight percent add-on would have to be increased accordingly. 
about ten, depending on agent presence) diameters, sometimes seeming to proceed in steps of about one diameter. Surface tension in the elongated glowing zone behind the leading front would periodically cause this part or all of this zone to contract into a sphere. The extent of contraction to a sphere depended on the presence of agent vapors, as discussed below. This sphere would frequently begin to eject numerous fine, glowing particles. When the mass of the sphere exceeded the tensile strength of the glowing zone to which it was attached, it dropped off, taking much of the glowing material away below the propagation front. The front nevertheless continued and the cycle repeated itself. This occurred 3 to 6 times during the course of a typical full length burn.

The enhanced heat release rate and/or heat transfer rate to the gas as the spheres developed and dropped was sometimes clearly visible in the output from the gas stream temperature sensor; Figure 3 shows such a case $e^{6}$ this is for $50 \%$ oxygen and $15 \%$ halon 1301 vapor. Note the ambiguity of the preceding attribution as to the cause of the spikes; the shape changes and varying area available for convective heat transfer may be mimicking variations in heat release rate. A further source of ambiguity in the signal from this sensor, caused by the dripping phenomenon, is a possible erratic contribution from drips which hit and stuck to the ignition electrodes ${ }^{7}$, continuing to burn for several seconds, rather than falling down into the quenching cup at the base of the chamber. Thus the output from this sensor has to be viewed with caution for the titanium tests; it cannot clearly differentiate heat release rate contributions from the primary burn zone from other sources of fluctuation. As a result, other data from this sensor are not reported here.

Figure 4a shows the simultaneous output (same test as Fig. 3) from the radiation thermopile viewing the sample through the back window of the chamber. The timing of the molten metal drips is indicated. Note that the halon 1301 vapor control valve was switched 8 seconds after the initial ignition spike and would be arriving in the neighborhood of the sample about one second later (at about 14 seconds on the time scale of Figure 4a). Except for the first drip, every drip is accompanied by a sharp drop in radiation output as the burning area shrinks sharply. As it builds up again, here in the form of a growing drop attached to the propagating front, the radiation again increases. However, each successive peak is smaller. It appears that the main reason for the monotonic peak shrinkage is erratic depositing of particles ejected from the burning zone on the rear chamber window, partially blocking some of the radiation. (The last peak is reduced by vignetting from the window frame.)

Figure $4 \mathrm{~b}$ shows the radiation sensor output for a case at the same conditions as in Fig. $4 \mathrm{a}$ except that there was no agent vapor present. The differing shape of the curve apparently corresponds to the different shape of the overall burning zone. When no agent was present, the burning zone consisted of several diameters of glowing rod, at the bottom of which the sphere of molten material accumulated before dropping off. When the sphere did drop off there was still an extensive glowing area that maintained the radiation signal at a fairly high level. When the agent vapors were present, as in Fig. 4a, the glowing rod section above the sphere was minimal in length leaving the sphere as the principal radiation source. When it dropped off the radiation signal dropped by a greater percentage. The mechanism whereby the agent vapors had this effect on the burning zone is not clear. One can speculate that it involves the relative rates of propagation (faster in the no-agent case) and of sphere formation.

${ }^{6}$ Time zero is arbitrary in this Figure; ignition occurs when the sensor signal becomes non-zero.

7he chamber was tilted backwards slightly to minimize the occurrence of this phenomenon but it could not be avoided entirely. 
In spite of these complications, there was a general tendency for the average radiation signal for the no-agent cases to be higher than for the cases with an agent vapor present. It is probable that this was due in part to the average temperature of the burning zone being hotter in the no-agent cases, but the confounding effects of shape changes and non-quantifiable window deposits make this unprovable with the available data. A lower burning zone temperature with the agent vapors present would, of course, be consistent with generally slower burning which Table 3 shows to occur in such cases, as compared to the no-agent cases.

Before proceeding to examine the titanium burning rate data further, it is of interest to make a simplified estimate of the potential effect on heat release rate from the burning metal due to participation of the agent vapors, if the burning process is taken to be mass-transfer limited. As was indicated previously, the data are not inconsistent with control by oxidant mass transfer through the boundary layer around the burn zone. The literature leads one to expect the impact of the agent to be burning rate enhancement. The source of such a potential burning rate or heat release rate enhancement is, of course, the higher heat of formation of the metal fluorides compared to the oxides.

Here we denote rate of heat release as $R H R$, where:

$$
R H R=m_{b} H_{0}=k A_{b}\left(Y_{o x, g a s}-Y_{o x, \text { surf }}\right) H_{0} / n_{0}
$$

Here $m_{b}$ is the mass burning rate of the metal $(\mathrm{g} / \mathrm{s}) ; H_{o}$ is the heat of combustion of the metal by oxygen per unit weight of metal burned $(\mathrm{J} / \mathrm{g}) ; n_{o}$ is the stoichiometric coefficient for oxidation $\left(\mathrm{g} \mathrm{O}_{2} / \mathrm{g}\right.$ metal burned); $k$ is the overall mass transfer coefficient between the flowing ambient atmosphere and the burning metal surface $\left(\mathrm{g} / \mathrm{cm}^{2} \mathrm{~s}\right) ; A_{b}$ is the burning area of the metal; $Y_{o x \text {,gas }}$ is the mass fraction of oxygen in the ambient gas and $Y_{a x, s u r f}$ is the mass fraction of oxygen at the surface of the burning metal. Note that $R H R$ and mass burning rate, $m_{b}$, are proportional; $R H R$ is generally a more relevant measure of fire intensity. When the agent vapors are also present in the ambient gas they potentially comprise a second oxidizer which can attack the metal surface in parallel with the oxygen. However, note that they also displace some oxygen. Then one can write the total heat release rate as:

$$
R H R^{\prime}=A_{b}\left(\left(H_{o} k_{0}\left(Y_{a x, g a s}^{\prime}-Y_{a x, \text { surf }}^{\prime}\right) / n_{0}+H_{a} k_{a}\left(Y_{a, g a s}-Y_{a \text { surf }}\right) / n_{a}\right)\right)
$$

Here subscript "a" refers to the agent vapors. Note also that the prime on the oxygen mass fraction symbols indicates that they have been changed from their values in Eqn. (1) by the addition of the agent vapor. That is,

$$
Y_{\text {oxpas }}^{\prime}=Y_{\text {ox,gas }} /\left(1+Y_{\text {agsas }}\right)
$$

If the chemistry involving both of the oxidizers is fast compared to their mass transfer rates through the boundary layer, the surface values of both become very small and can be dropped. We can estimate the effect of the agent addition by taking the ratio of Eqn. (1) to Eqn. (2): 


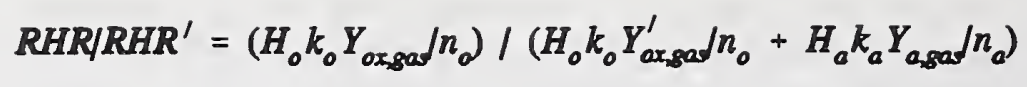

Note that the burn area parameter has been cancelled out on the assumption that it is unaffected by the agent vapor. The discussion above regarding the radiation output implies that the average burn area probably does decrease somewhat in the presence of the agent vapor but there is no way to quantify this at present. After dividing through, one obtains the following expression.

$$
R H R / R H R^{\prime}=Y_{\text {ox, }} /\left(Y_{\text {ox }}^{\prime}+\left(H_{d} / H_{0}\right)\left(k_{d} / k_{0}\right)\left(n_{d} / n_{a}\right) Y_{a, g a s}\right)
$$

Now it is possible to see that the effect of an add-on mass fraction of amount $\mathrm{Y}_{\mathrm{a} \text {,gas }}$ is modulated not only by the relative heat of reaction but also by the relative rate at which these new molecules can diffuse to the reaction zone and by the relative mass which must diffuse there (dictated by the reaction stoichiometry). The diffusion coefficients differ because the agent is typically a much bigger molecule than oxygen. Using diffusivity data for naphthalene and anthracene as molecules of appropriate weight, and a mid-temperature estimate in the boundary layer of $1500^{\circ} \mathrm{C}$, one finds that $\left(k_{a} / k_{o}\right)$ is about $1 / 3$. For halon 1301 versus oxygen, $\left(n_{d} / n_{a}\right)$ is 0.216 ; for HFC-125 it is 0.335 (both based on the type of overall reaction indicated below).

An estimate of $H_{a}$ requires that some estimate of the products be made for the interaction with the agent vapor. Lacking the requisite thermodynamic data to make detailed equilibrium calculations for this system, we assume the following plausible overall reaction scheme for halon 1301.

$$
4 \mathrm{Ti}+4 \mathrm{O}_{2}+4 \mathrm{CF}_{3} \mathrm{Br} \rightarrow 3 \mathrm{TiF}_{4}+\mathrm{TiBr}_{4}+4 \mathrm{CO}_{2}
$$

The evolved heat from this reaction is $1.06 \mathrm{MJ} / \mathrm{g}$-mole of titanium, $16 \%$ higher than that for titanium dioxide formation. A comparable calculation for HFC-125 yields an estimate that is about $50 \%$ greater than for $\mathrm{TiO}_{2}$ formation. (Necessary data on the heat of formation for HFC-227 could not be found so an estimate for this agent has not been made.) Note that the above overall reaction implies that there is some competition of the agent vapor for the oxygen that is diffusing to the metal surface since the carbon in the agent is oxidized in the gas phase. Thus there is not a clean separation into two purely parallel, non-interacting paths of attack by the two oxidizing agents, as assumed in Eqn. (2). It seems likely that some of the carbon dioxide formed in the boundary layer would lose its oxygen to the titanium when it diffuses to the surface; this would somewhat lower the overall exotherm of the above reaction scheme and counter the effects of the neglected interaction. Any dissociation of the products would also lower the available heat.

With these caveats, one can use the preceding reaction heats in Eqn. (5) to estimate that the heat release rate effect for a $10 \%$ add-on of halon 1301 is a net decrease of about $6 \% .^{8}$ For a $10 \%$ addon of HFC- 125 , the estimated decrease in RHR is about $2 \%$. The estimated changes in mass burning rate are comparable. Given the various assumptions that went into these estimates they are probably

\footnotetext{
${ }^{8} \mathrm{~A}$ comparable calculation for magnesium and halon 1301 yields a $4 \%$ decrease in $R H R$ but one should note that the model assumptions are less appropriate here due to the gas phase chemistry, rather than heterogeneous chemistry.
} 
accurate to no better than $\pm 50 \%$. (Furthermore, the model predictions cannot be any more accurate than the underlying assumptions allow them to be.) In any event, for the add-on levels of the order of $10 \%$ they do predict a small slow-down of the burning process.

The reason that this prediction runs counter to the heat release enhancement one might expect is implicit in the main assumption behind the simplified model. Oxidant mass transfer is taken to be the rate controlling step. The large agent molecules cannot diffuse to the reaction zone at more than a fraction of the rate at which oxygen can. The displacement of some oxygen by the agent vapor reduces the titanium dioxide production rate and heat release; the halogen reactions, retarded by the relatively slow agent molecules, cannot proceed fast enough to make up the difference, in spite of their energetic advantage.

This simple model can make a prediction of what add-on level of agent would be needed to yield a net increase in heat release rate. This just implies that the denominator exceeds the numerator in Eqn. (5). Interestingly, the model says that for halon 1301 there is no add-on level of this agent which can achieve a greater heat release rate than one gets with oxygen as the sole oxidant gas; this holds for oxygen levels from that in air up to at least 50\%. ${ }^{9}$ For HFC-125 the model says that this agent will yield a RHR enhancement at add-ons above about $40 \%$ if the starting gas is air; there is no add-on level capable of yielding enhancement when the starting gas has $40 \%$ or $50 \%$ oxygen.

The above estimates of the impact of agent addition stand in contrast to the actual observed behavior as shown in Table 3. As with magnesium, the actual effect of the agent vapors in all cases was strongly suppressive, not just slightly so. The reasons behind this are difficult to discern, given the limited data. The strong effect suggests a greater role for chemistry than the above model allows. Perhaps the oxidation reactions are more marginal (and thus more controlling) than has been assumed or there are suppressive chemical effects of the agent on the metal burning which are not known to the present authors.

In titanium burning, nitrogen is somewhat more akin to an inert diluent than it was with magnesium because the heat of formation of titanium nitride is one third that of titanium dioxide. Table 3 shows that a $10 \%$ nitrogen add-on yields a $17 \%$ reduction in burning rate (in $40 \%$ oxygen at $0.79 \mathrm{MPa}$ ). A $10 \%$ add-on of halon 1301 (with only about half of the thermal capacitance of the nitrogen add-on) yields either a much greater burning rate reduction or even extinction. ${ }^{10}$ A $10 \%$ add-on of HFC-125 gave very erratic results under these same conditions, from no effect to extinction. (The pressure variation in these tests was the result of partial clogging of the downstream orifice by particles emitted from the burning titanium.) In terms of thermal capacitance or ability to lower temperature by pure dilution, a $10 \%$ add-on of nitrogen is comparable to HFC-125 and about twice as effective as halon 1301. These results thus suggest that the apparent suppressive effects of the agents are beyond simple thermal dilution and well beyond the calculated effects if mass transfer was the controlling mechanism.

The ambient oxygen level was increased to $50 \%$ so that the chamber pressure could be lowered to the point where HFC-227, with its comparatively low vapor pressure, could be tested alongside HFC125 and halon 1301. Table 3 shows that the more vigorous burning that resulted from the oxygen

\footnotetext{
${ }^{9}$ For magnesium and halon 1301 , this calculation says that agent add-on levels to air of nearly $80 \%$ are needed to yield an increase in heat release rate above that found in pure air.

${ }^{10}$ The extinction process here occurred after $50-80 \%$ of the rod had burned and thus was much more marginal than in the case of magnesium. It occurred when the burn zone was in the contracted molten ball stage. A build-up of titanium dioxide near the ball surface (Clark et al., 1975) could make this a slower reaction stage and thus a more vulnerable part of the burning cycle.
} 
enhancement resisted extinguishment by any of these agents. However, they again all slowed the burning process strongly. Here halon 1301 and HFC-125 appear about equally effective in slowing the burning. HFC-227 is distinctly less effective, though this inference is based on very limited data. One might cautiously extrapolate this result to infer that HFC-125 would produce a lesser hazard in aircraft applications than would HFC-227 but more data on this issue would certainly be desirable.

Again it is necessary to add the caveat noted previously with the magnesium results. The ability of these agent vapors to partially suppress the burning of titanium in the present experimental conditions does not mean that they will do so in a more complex burning configuration or at all admixture levels. Also, any agent sprayed at a metal fire in liquid form has the potential to cause a flare-up due solely to droplet "explosions" which could enlarge the metal area exposed to oxidation. It was not possible to test the role of this factor in the confines of the present study.

\section{Conclusions}

Halon 1301 (the reference case), as well as the candidate replacement agents HFC-125, HFC-227, FC218 and $\mathrm{CF}_{3} \mathrm{I}$, extinguished the strongly- established burning of thin rods of magnesium when addedon at the 5 and $10 \%$ level to pressurized air flowing past the burn zone. In nearly all cases the extinction occurred in a matter of seconds. FC-218 was appreciably slower in causing extinction in two replicate tests at one condition; this was the only differentiation among the various agents seen with burning magnesium. In this sense the candidate replacement agents, other than FC-218, have shown no greater tendency to interact with burning magnesium than does halon 1301.

The general suppressive effect on magnesium burning runs counter to the burning enhancement effects reported in the literature for halogen-containing compounds sprayed onto more complex magnesium burning configurations. A simplified calculation, based on the assumption of mass transfer control of the burning rate and an assumed reaction stoichiometry, suggests that a very weak suppressive effect could be expected here, largely as a result of oxygen dilution. The cause of the much stronger suppressive effects seen here is not clear at present. This same calculation suggests that enhancement of magnesium burning could occur at much higher agent add-on levels.

Halon 1301, HFC-125 and HFC-227 also showed substantial suppressive capabilities toward the burning of a thin titanium rod in elevated oxygen atmospheres. Here extinction was seen only in $40 \%$ oxygen, not in 50\% oxygen. Nevertheless, even at the higher oxygen level, substantial reductions in burn propagation rate were seen. Here HFC-125 at a $15 \%$ add-on level slowed the burn rate equally as much as did halon 1301 and much more than did HFC-227. This was the only differentiation among agents seen with titanium burning. It provides a very limited basis on which to infer that HFC125 might be less reactive with titanium fires than HFC-227 (and comparable to halon 1301).

The simplified calculation, mentioned above but here done only for halon 1301 and HFC-125, again implies only a very weak suppressive effect of 10 to $15 \%$ add-on levels of these agents, via oxygen dilution. The much stronger effect seen experimentally cannot be explained on the basis of the available information. This calculation implies that, at elevated oxygen levels, no add-on level of agent can yield burning enhancement. In air, according to this model, HFC-125 could yield enhancement of the burning rate at add-on levels above $40 \%$. This raises a note of caution about the relatively lower reactivity of HFC-125 compared to HFC-227 seen here, due to the limited number of hard facts available.

Since the results here for isolated, single metal rods run counter to the reported effects of halogen-containing agents on more massive magnesium and titanium fires, it appears that further experiments would be desirable, involving larger masses of burning metal, preferably in a linear burning mode as here, but incorporating radiative interchange among fuel elements. This would allow 
quantitation of the burning progress, allowing definitive determination of the impact of agent vapors and agent liquid/vapor sprays. Pre-heating and pressurization of the gas stream would also make it possible to adhere to oxygen levels closer to air with titanium so that one could determine more definitively the impact of halogen-containing agents under conditions most pertinent to jet aircraft fires.

\section{References}

Anderson, V. and Manty, B., "Titanium Alloy Ignition and Combustion," Naval Air Development Center Report No. NADC 76083-30, Warminster, Penn., January, 1978

Andrews, R., "Metals," Section 4, National Fire Protection Handbook, Fifteenth Edition, Chap.

10, Section 4, National Fire Protection Association, Quincy, Mass., p. 4-98, (1981)

Baldwin, J., Beach, C. and Rhein, R., "Extinction of Titanium Fires in Pressurized Flowing Air," Naval Weapons Center Report No. NWC TP 6439, China Lake, Calif., Sept., 1984

Bird, B. Stewart, W. and Lightfoot, E., Transport Phenomena, Wiley, New York, p. 647 (1960)

Clark, A., Moulder, J. and Runyan, C., "Combustion of Bulk Titanium in Oxygen," Fifteenth Symposium (International) on Combustion, The Combustion Institute, Pittsburgh, Penn., p. 489 (1975)

Elrod, C., Funkhauser, M. and Glickstein, M., "Compendium on Titanium Combustion," Air Force Wright Aeronautical Laboratories Report No. AFWAL-TR-82-2014, Wright-Patterson Air Force Base, Ohio, Nov., 1980

Elrod, C. and Lyon, S., "Self-Sustained Combustion Evaluation of Titanium 6Al-4V in an Aerodynamic Environment," Air Force Wright Aeronautical Laboratories Report No. AFAPL-TR-792047, Wright-Patterson Air Force Base, Ohio, August, 1976

Fox, D., "Investigation of Titanium Combustion Characteristics and Suppression Techniques," Air Force Wright Aeronautical Laboratories Report No. AFAPL-TR-75-73, Wright-Patterson Air Force Base, Ohio, July, 1975

Hamins, A., Gmurczyk, Grosshandler, W., Rehwoldt, G., Vazquez, I., Cleary, T., Presser, C. and Seshadri, K., "Flame Suppression Effectiveness," Chapter 4 in "Evaluation of Alternative Fire Suppressants for Full-Scale Testing in Simulated Aircraft Engine Nacelles and Dry Bays," National Institute of Standards and Technology Special Publication 861, April, 1994

Kuchta, J. Martindill, G. and Spolan, I., "Fire and Explosion Hazards

of Flight Vehicle Combustibles," Quarterly Progress, U. S. Bureau od Mines, Pittsburgh, Penn., June to August, 1965

ibid, November to February, 1966

Law, C. and Williams, F., "Combustion of Magnesium Particles in Oxygen-Inert Atmospheres," Combustion and Flame, 22, p. 383 (1974)

Maykuth, D., "Methods of Controlling and Extinguishing Titanium Fires," Defense Metals Information Institute Technical Note, Batelle Memorial Institute, Columbus, Ohio, July, 1964

McCutchan, R., "Investigation of Magnesium Fire-Extinguishing Agents," Wright Air Development Center Technical Report 54-5, Wright-Patterson Air Force Base, Ohio, Jan., 1954

National Aeronautics and Space Administration, "Detonation Hazards with 'Safe' Industrial Solvents," NASA Langley Research Center LAR-10299, Hampton, Virginia, 1970

Nyden, M., Linteris, G,. Burgess, D., Westmoreland, P., Tsang, W. and Zachariah. M., "Flame Inhibition Chemistry and the Search for Additional Fire Fighting Chemicals," Chapter 5 in "Evaluation of Alternative Fire Suppressants for Full-Scale Testing in Simulated Aircraft Engine Nacelles and Dry Bays," National Institute of Standards and Technology Special Publication 861, April, 1994 
Perlee, H., Martindill, G. and Zabetakis, M., "Flammability Characteristics of Selected Halogenated Hydrocarbons," U. S. Bureau of Mines TN23.U7, Pittsburgh, Penn., 1966

Rhein, R. and Baldwin, J., "Literature Review on Titanium Combustion and Extinction," Naval Weapons Center Report No. NWC TP 6167, China Lake, Calif., Jan., 1980

Sato, J. and Hirano, T., "Fire Spread Limits Along Metal Pieces in Oxygen," Flammability and Sensitivity of Materials in Oxygen-Enriched Environments: Third Volume, ASTM STP 986, D. Scroll (ed.), American Society for Testing and Materials, Philadelphia, Penn., p. 158 (1988)

Sato, J., Sato, K. and Hirano, T., "Fire Spread Mechanisms along Steel Cylinders in High Pressure Oxygen," Combustion and Flame, 51, p. 279 (1983)

Strobridge, T., Moulder, J. and Clark, A., "Titanium Combustion in Turbine Engines," Federal Aviation Administration Report No.FAA-RD-79-51, Washington, D.C., July, 1979

Tapscott, R., Beeson, H., Lee, M., Plugge, M., Zallen, D., Walker, J, and Campbell, P., "Extinguishing Agent for Magnesium Fire: Phases I-IV," New Mexico Engineering Research Institute Report WA3-15, Albuquerque, New Mexico, July, 1986 
TABLE 1. MAGNESIUM BURNING IN PRESSURIZED AIR

\begin{tabular}{|c|c|c|c|c|c|}
\hline $\begin{array}{c}\text { TEST } \\
\text { I.D. }\end{array}$ & AMBIENT GAS & $\begin{array}{c}\text { MASS FLOW } \\
\text { RATE OF GAS } \\
(\mathrm{g} / \mathrm{s})\end{array}$ & $\begin{array}{c}\text { GAS } \\
\text { FLOW } \\
\text { VELOCITY } \\
(\mathrm{cm} / \mathrm{s})\end{array}$ & $\begin{array}{l}\text { CHAMBER } \\
\text { PRESSURE } \\
\text { (MPa/psig) }\end{array}$ & $\begin{array}{l}\text { BURN } \\
\text { RATE } \\
(\mathbf{m m} / \mathbf{s})\end{array}$ \\
\hline $\mathrm{Mg}-24$ & AIR & 1.89 & 42 & $0.24 / 20$ & 3.66 \\
\hline$M g-24$ & $"$ & $"$ & 22 & $0.44 / 50$ & 4.23 \\
\hline $\mathrm{Mg}-4$ & $"$ & $"$ & 13 & $0.79 / 100$ & 4.14 \\
\hline Mg-5 & $"$ & $"$ & $"$ & $"$ & 3.75 \\
\hline $\mathrm{Mg}-50$ & $"$ & 1.89 & 36 & $0.27 / 25$ & 4.14 \\
\hline $\mathrm{Mg}-52$ & $"$ & $"$ & " & $"$ & 3.45 \\
\hline$M g-53$ & $"$ & $"$ & " & $"$ & 3.33 \\
\hline Mg-16 & $\begin{array}{l}\text { AIR + NITROGEN } \\
(10 \% \text { ADD-ON })\end{array}$ & 1.46 & 13.9 & $0.79 / 100$ & 3.75 \\
\hline Mg-19 & $"$ & $"$ & $"$ & $"$ & 3.53 \\
\hline $\mathrm{Mg}-26$ & $"$ & $"$ & " & $"$ & 3.57 \\
\hline
\end{tabular}




\section{TABLE 2. MAGNESIUM BURNING IN PRESSURIZED AIR WITH AGENT VAPOR ${ }^{11}$}

\begin{tabular}{|c|c|c|c|c|}
\hline TEST I.D. & $\begin{array}{c}\text { AGENT } \\
\text { (ADD-ON, } \\
\text { WGT \%) }\end{array}$ & $\begin{array}{c}\text { GAS FLOW } \\
\text { VELOCITY } \\
(\mathrm{cm} / \mathrm{s})\end{array}$ & $\begin{array}{c}\text { CHAMBER } \\
\text { PRESSURE } \\
\text { (MPa/psig) }\end{array}$ & $\begin{array}{l}\text { BURN RATE } \\
(\mathrm{mm} / \mathrm{s})\end{array}$ \\
\hline Mg-11,12,13,14 & $\begin{array}{c}\text { HALON-1301 } \\
(10 \%)\end{array}$ & 13 & $0.79 / 100$ & EXTING. \\
\hline $\mathrm{Mg}-25,26,27$ & $"$ & 37 & $0.27 / 25$ & EXTING. \\
\hline $\mathrm{Mg}-47,48$ & $\begin{array}{c}\text { HALON-1301 } \\
(5 \%)\end{array}$ & 13 & $0.79 / 100$ & EXTING. \\
\hline $\mathrm{Mg}-39,40$ & $"$ & 37 & $0.27 / 25$ & EXTING. \\
\hline $\mathrm{Mg}-41,42$ & HFC-125 (5\%) & 13 & $0.79 / 100$ & EXTING. \\
\hline $\mathrm{Mg}-37,38$ & $"$ & 37 & $0.27 / 25$ & EXTING. \\
\hline $\mathrm{Mg}-39,40$ & HFC-227 (5\%) & 37 & $0.27 / 25$ & EXTING. \\
\hline $\mathrm{Mg}-30,31$ & FC-218 (10\%) & 37 & $0.27 / 25$ & EXTING. \\
\hline $\mathrm{Mg}-43,44,45$ & FC-218 (5\%) & 14 & $0.72 / 90$ & EXTING. \\
\hline $\mathrm{Mg}-32,33$ & $"$ & 37 & $0.27 / 25$ & EXTING. \\
\hline $\mathrm{Mg}-34,35,36$ & $\mathrm{CF}_{3} \mathrm{I}(5 \%)$ & 37 & $0.27 / 25$ & EXTING. \\
\hline & & & & \\
\hline
\end{tabular}

${ }^{11}$ Air mass flow rate held constant at $1.33 \mathrm{~g} / \mathrm{s}$ for all tests. 
TABLE 3. TITANIUM BURNING IN ELEVATED OXYGEN ATMOSPHERES

\begin{tabular}{|c|c|c|c|c|c|}
\hline $\begin{array}{l}\text { TEST } \\
\text { I.D. }\end{array}$ & $\begin{array}{l}\text { WEIGHT } \\
\text { PERCENT } \\
\text { OXYGEN }^{12}\end{array}$ & $\begin{array}{c}\text { CHAMBER } \\
\text { PRESSURE } \\
\text { (MPa/psig) }\end{array}$ & $\begin{array}{c}\text { GAS FLOW } \\
\text { VELOCITY } \\
(\mathrm{cm} / \mathrm{s})\end{array}$ & $\begin{array}{l}\text { AGENT } \\
\text { (ADD-ON } \\
\text { WGT \%) }\end{array}$ & $\begin{array}{l}\text { BURN RATE } \\
(\mathbf{m m} / \mathbf{s})\end{array}$ \\
\hline $\begin{array}{l}\text { Ti-14 } \\
\text { Ti-15 }\end{array}$ & 40 & $0.79 / 100$ & 13 & NONE & $\begin{array}{l}1.85 \\
1.94\end{array}$ \\
\hline $\begin{array}{l}\text { Ti-20 } \\
\text { Ti-21 }\end{array}$ & $"$ & " & 14 & $\begin{array}{c}\text { NITROGEN } \\
(10 \%)\end{array}$ & $\begin{array}{l}1.63 \\
1.67\end{array}$ \\
\hline $\begin{array}{l}\text { Ti-16 } \\
\text { Ti-18 } \\
\text { Ti-19 }\end{array}$ & $"$ & $"$ & 13 & $\begin{array}{c}\text { HALON-1301 } \\
(10 \%)\end{array}$ & $\begin{array}{c}1.11 \\
\text { EXTING. } \\
\text { EXTING. }\end{array}$ \\
\hline $\begin{array}{l}\text { Ti-22 } \\
\text { Ti-23 } \\
\text { Ti-24 } \\
\text { Ti-25 }\end{array}$ & $"$ & $\begin{array}{c}" \\
0.79-0.91 \\
" \\
0.79-0.95\end{array}$ & 12 & $\begin{array}{c}\text { HFC-125 } \\
(10 \%)\end{array}$ & $\begin{array}{c}1.57 \\
\text { EXTING. } \\
\text { EXTING. } \\
1.92\end{array}$ \\
\hline $\begin{array}{l}\text { Ti-39 } \\
\text { Ti-40 }\end{array}$ & 50 & $0.38 / 40$ & 33 & NONE & $\begin{array}{l}2.53 \\
2.59\end{array}$ \\
\hline $\begin{array}{l}\text { Ti-39 } \\
\text { Ti-48 }\end{array}$ & $"$ & $"$ & 34 & $\begin{array}{c}\text { HALON } 1301 \\
(15 \%)\end{array}$ & $\begin{array}{l}1.07 \\
1.05\end{array}$ \\
\hline $\begin{array}{l}\text { Ti-34 } \\
\text { Ti-36 }\end{array}$ & $"$ & $"$ & 34 & $\begin{array}{c}\text { HFC-125 } \\
(15 \%)\end{array}$ & $\begin{array}{l}1.07 \\
0.96\end{array}$ \\
\hline $\begin{array}{l}\text { Ti-32 } \\
\text { Ti-33 }\end{array}$ & $"$ & " & 34 & $\begin{array}{c}\text { HFC-227 } \\
(15 \%)\end{array}$ & $\begin{array}{l}1.88 \\
1.90\end{array}$ \\
\hline $\begin{array}{l}\text { Ti-26 } \\
\text { Ti-27 }\end{array}$ & 50 & $0.38 / 40$ & 27 & NONE & $\begin{array}{l}2.48 \\
2.41\end{array}$ \\
\hline $\begin{array}{l}\text { Ti-28 } \\
\text { Ti-29 }\end{array}$ & $"$ & $"$ & 28 & $\begin{array}{c}\text { HALON } 1301 \\
(15 \%)\end{array}$ & $\begin{array}{l}1.24 \\
1.20\end{array}$ \\
\hline
\end{tabular}

${ }^{12}$ This is the oxygen percentage by weight in the oxidant gas flow exclusive of the presence of the agent. 


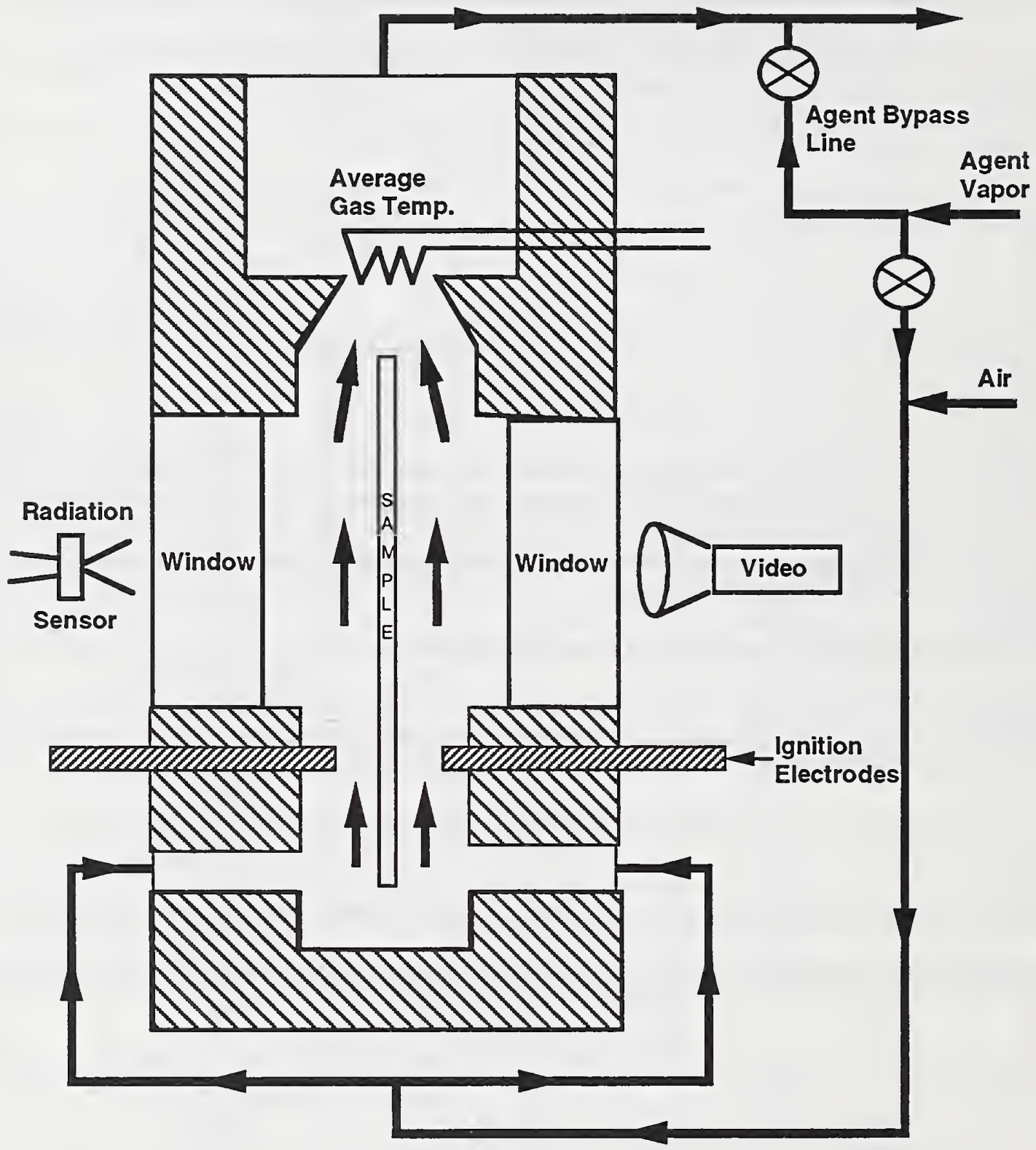

FIGURE 1a. SCHEMATIC OF METAL COMBUSTION EXPERIMENT 


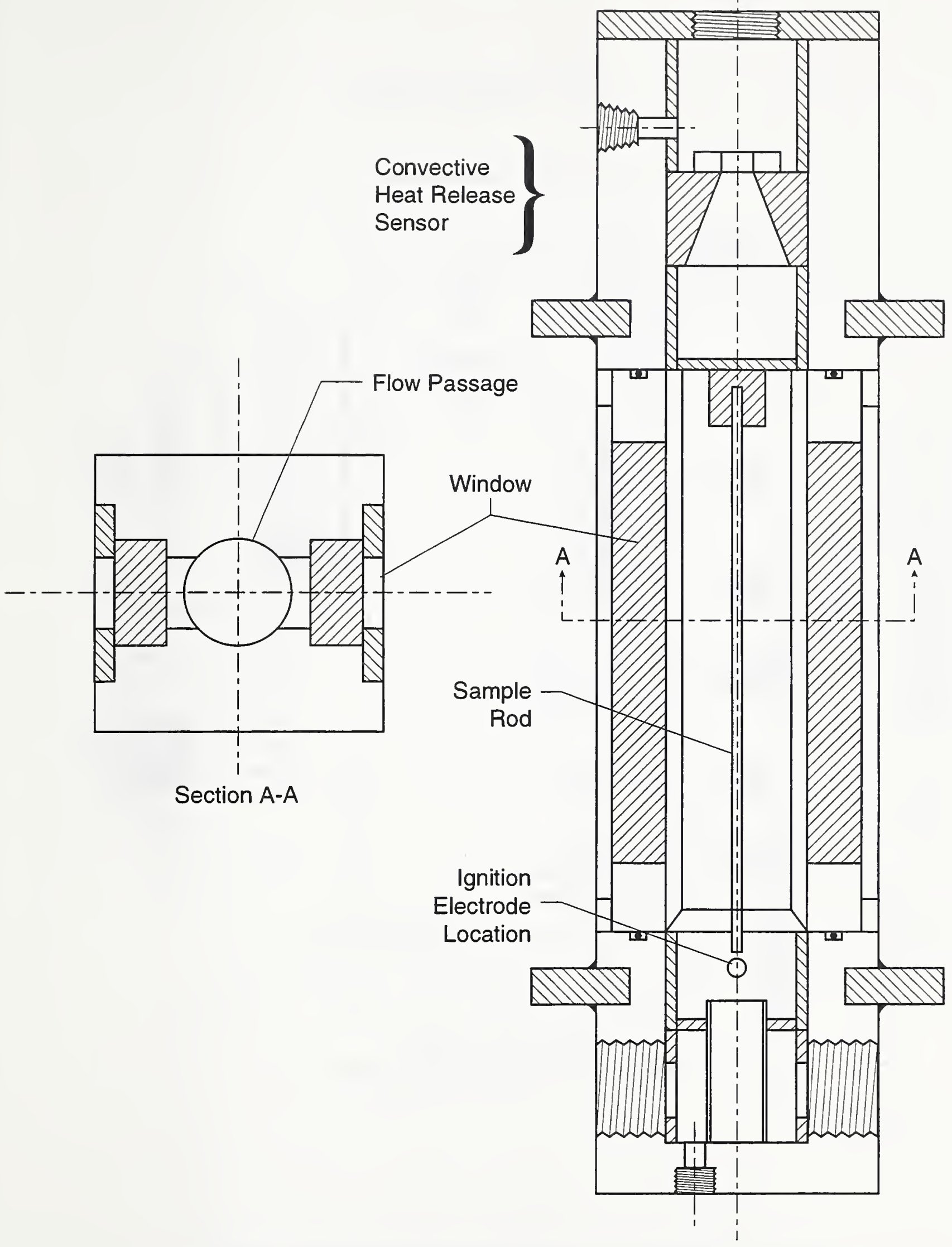

Figure 1b. One-half scale assembly drawing of combustion chamber 


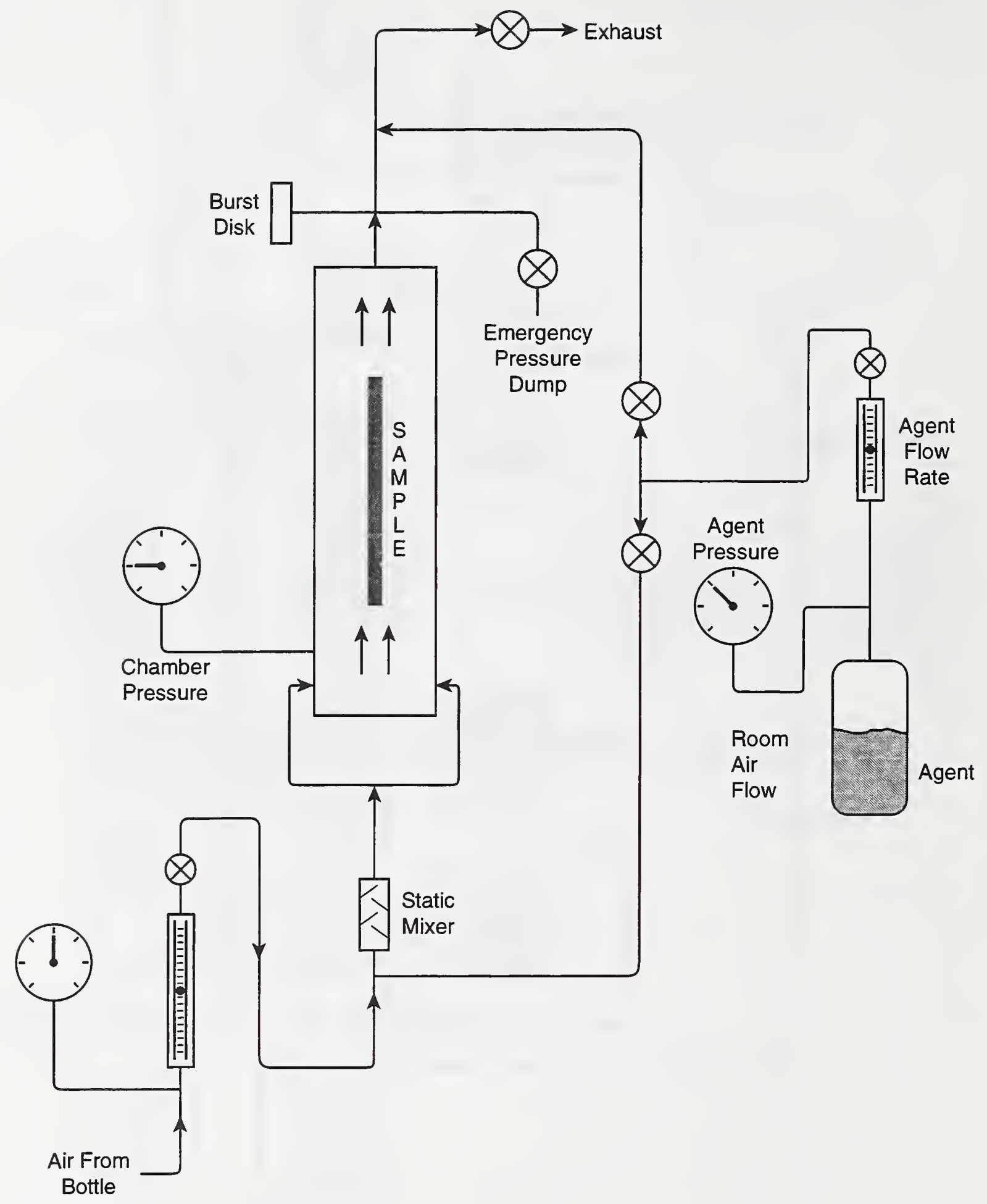

Figure 2. Flow system associated with combustion chamber 


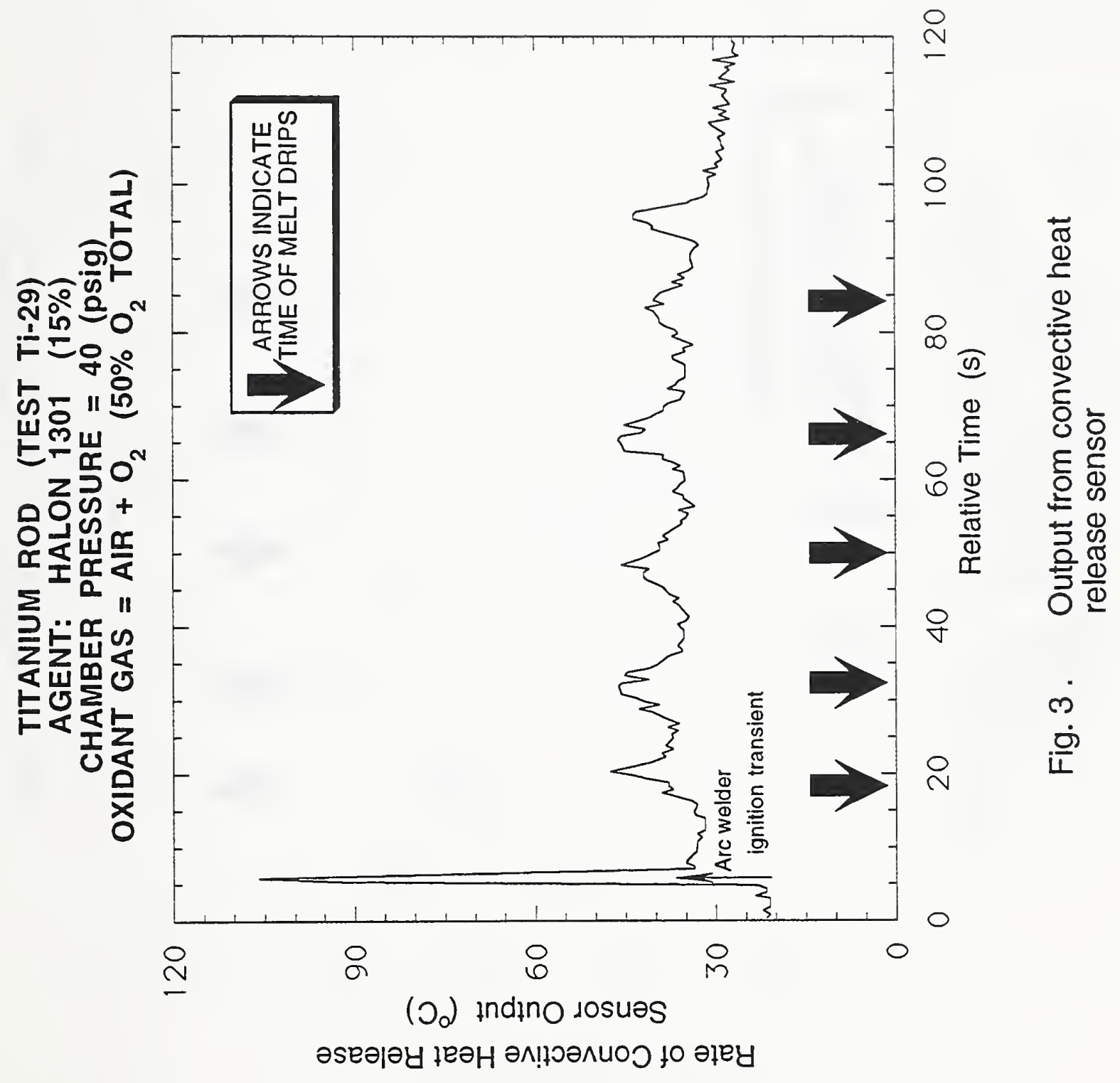




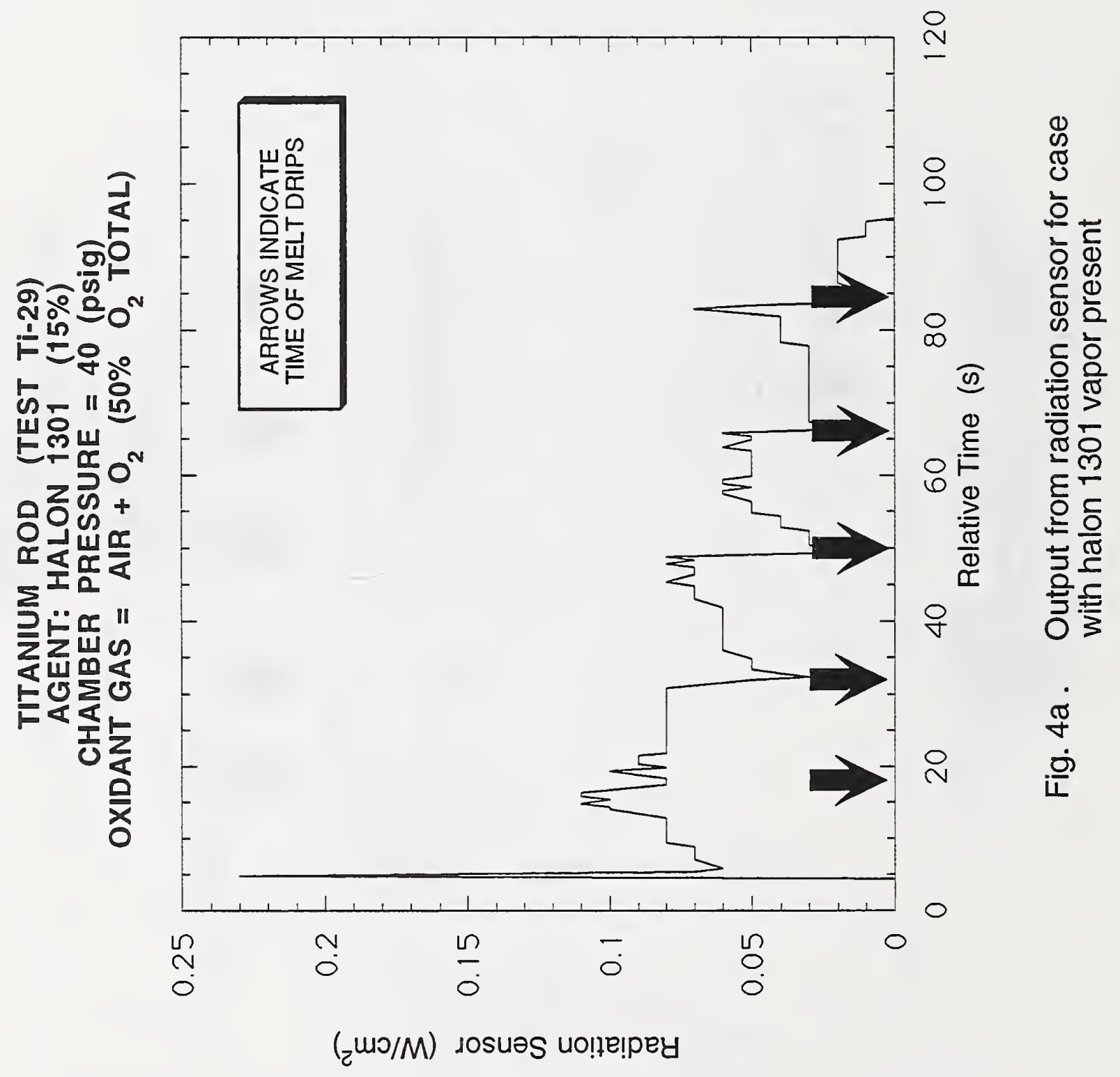




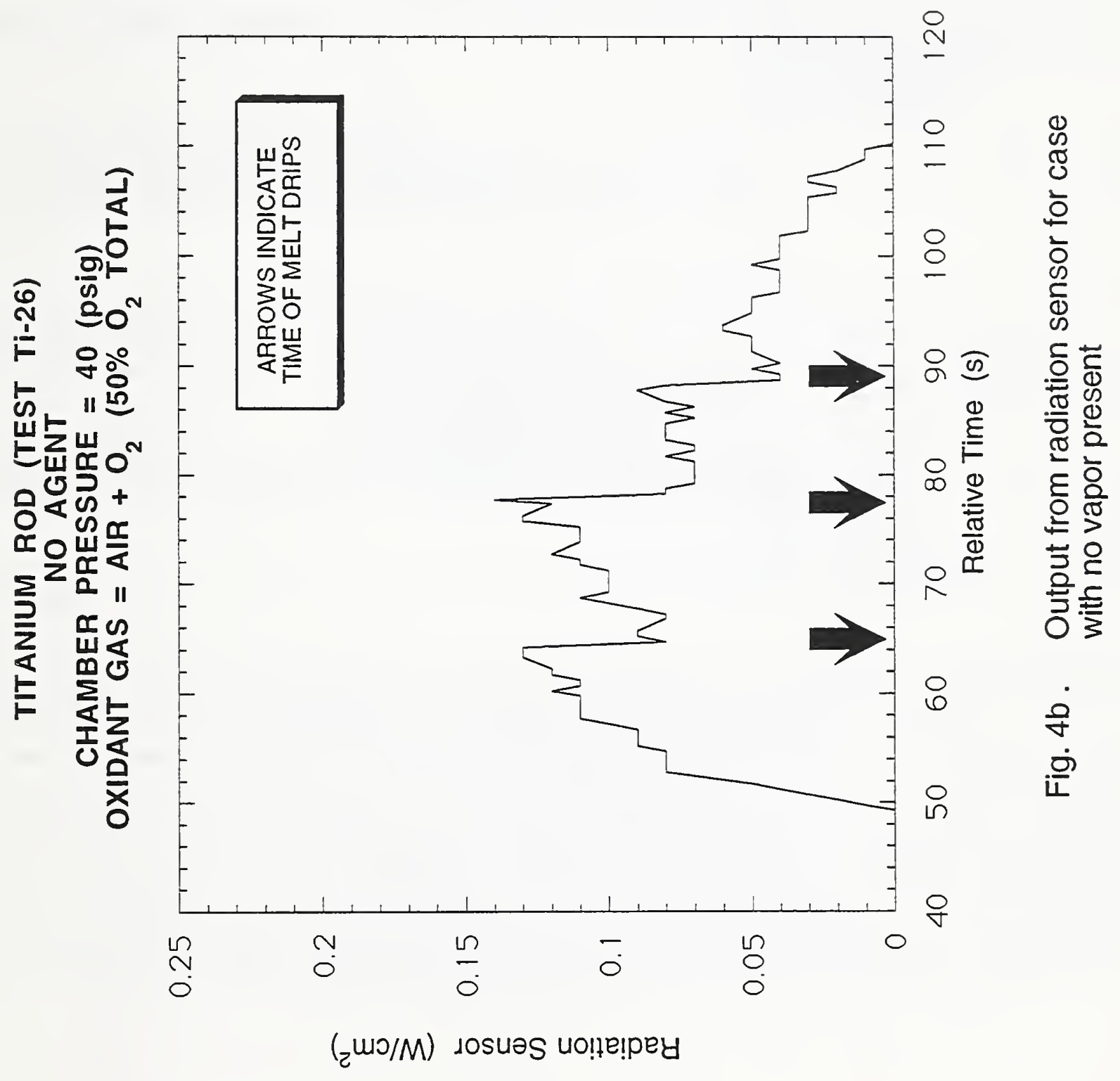





\section{NIST-114 \\ (REV. 6-93) \\ ADMAN 4.09 \\ MANUSCRIPT REVIEW AND APPROVAL}

INSTRUCTIONS: ATTACH ORIGINAL OF THIS FORM TO ONE (1) COPY OF MANUSCRIPT AND SEND TO THE SECRETARY, APPROPRIATE EDITORIAL REVIEW BOARD

TITLE AND SUBTITLE (CITE IN FULL)

Effect of Suppressants on Metal Fires

CONTRACT OR GRANT NUMBER

TYPE OF REPORT AND/OR PERIOD COVERED

AUTHOR(S) (LAST NAME, FIRST INITIAL, SECOND INITIAL)

Oblemiller, T. J.

Shields, J. R.

LABORATORY AND DIVISION NAMES IFIRST NIST AUTHOR ONLY)

Building and Fire Research Laboratory, Fire Science Division

SPONSORING ORGANIZATION NAME AND COMPLETE ADDRESS (STREET, CITY, STATE, ZIP)

\section{PROPOSED FOR NIST PUBLICATION}

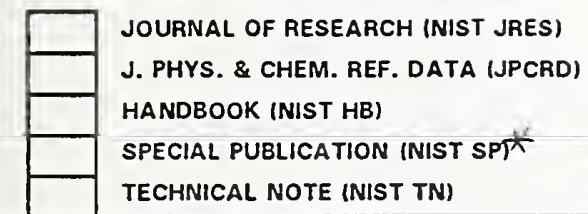

PROPOSED FOR NON-NIST PUBLICATION (CITE FULLY)

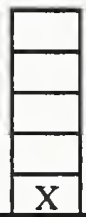

MONOGRAPH (NIST MN)

NATL. STD. REF. DATA SERIES (NIST NSRDS)

FEDERAL INF. PROCESS. STDS. (NIST FIPS)

LIST OF PUBLICATIONS INIST LP)

NIST INTERAGENCYINTERNAL REPORT (NISTIR)
(ERB USE ONLY)

\begin{tabular}{|l|l}
\hline ERB CONTROL NUMBER & DIVISION
\end{tabular}

PUBLICATION REPORT NUMBER

NISTIR 5710

PUBLICATION DATE

NUMBER PRINTED PAGES

August 1995

.

ER

\begin{tabular}{l|l|l|l}
$\square$ & U.S. \\
\hline
\end{tabular}

PAPER DISKETTE (SPECIFY)

LETTER CIRCULAR BUILDING SCIENCE SERIES PRODUCT STANDARDS OTHER OTHER (SPECIFY)

SUPPLEMENTARY NOTES

ABSTRACT (A 200O-CHARACTER OR LESS FACTUAL SUMMARY OF MOST SIGNIFICANT INFORMATION. IF DOCUMENT INCLUDES A SIGNIFICANT BIBLIOGRAPHY OR LITERATURE SURVEY, CITE IT HERE. SPELL OUT ACRONYMS ON FIRST REFERENCE.) (CONTINUE ON SEPARATE PAGE, IF NECESSARY.)

As part of a study to determine the impact of halon-alternative fire suppression agents on metal fires, small diameter rods (ca. 1-2 $\mathrm{mm}$ ) of magnesium and titanium were burned in oxidizing atmospheres containing various percentages of agent vapor. Magnesium was burned in flowing air at pressures of 0.27 and $0.79 \mathrm{MPa}(25$ and $100 \mathrm{psig})$. Add-on levels of $5 \%$ and, in some cases $10 \%$, by weight of halon 1301, HFC-125, HFC-227, FC-218 and $\mathrm{CF}_{3} \mathrm{I}$ were examined. In all cases, the burning, which had been vigorously established before agent vapor introduction, was extinguished. Titanium was burned in a flowing oxidizing gas containing 40 to $50 \%$ oxygen in nitrogen at pressures from 0.31 to $0.79 \mathrm{MPa}$ (30 to $100 \mathrm{psig}$ ). Here only halon 1301, HFC-125 and HFC-227 were added on, at $10 \%$ and $15 \%$ by weight. All three of these agents slowed, or, in certain cases extinguished, the burning process. Very limited data showed HFC-227 to slow the burning rate less than did an equal add-on of HFC-125 or halon 1301. The suppressive impact of the agent vapors seen in this study is counter to that in previous studies where burning enhancement has been seen.

KEY WORDS (MAXIMUM OF 9; 28 CHARACTERS AND SPACES EACH; SEPARATE WITH SEMICOLONS; ALPHABETIC ORDER; CAPITALIZE ONLY PROPER NAMES) halon; magnesium burning; metal fires; suppression; titanium burning.

\section{AVAILABILITY}

AVAN
UNLIMITED $\square$ FOR OFFICIAL DISTRIBUTION - DO NOT RELEASE TO NTIS ORDER FROM SUPERINTENDENT OF DOCUMENTS, U.S. GPO, WASHINGTON, DC 20402 ORDER FROM NTIS, SPRINGFIELD, VA 22161
NOTE TO AUTHOR(S): IF YOU DO NOT WISH THIS MANUSCRIPT ANNOUNCED BEFORE PUBLICATION, PLEASE CHECK HERE. 


